\title{
ELECTIONS TO THE PRINCIPAL EXECUTIVE COMMITTEE OF THE BRITISH DENTAL ASSOCIATION - NOTICE OF BY ELECTION IN WEST MIDLANDS
}

There is a vacancy on the Principal Executive Committee for the member from the West Midlands region.

This notice constitutes a fresh call for nominations for a by election in the West Midlands to fill the vacancy. A downloadable nomination form is available on the BDA website at www.bda.org/dentists/representation/governance/pec. If you want a hard copy election pack sent to you, contact Alison Magee by emailing your request to a.magee@bda.org or telephoning 02075355833.

Completed nomination forms must be returned by 12 noon Thursday 27 February 2014.

The Principal Executive Committee (PEC)

The PEC has overall responsibility for the control and direction of the policy and affairs of the Association, and its members are the Directors of the Association.

There are 12 members of the PEC apart from the senior officers such as the Chair, and it is anticipated that each will have a fair share of overall responsibilities.

Typically this will require:

- Attendance at all meetings of the PEC - around five a year, but maybe more when business demands

- Attendance at own country council meetings

- Attendance at UK Council meetings

- Sit on 1-2 sub committees/issue specific forums

- Attend general meetings of the Association

It is anticipated that the approximate time commitment for an ordinary PEC member will be 20 days per year, with an annual remuneration of $£ 15,000$.

Term of office

This shall be until December 2014, with the entitlement to stand for a full three year term of office at that point.

Induction, support and training

Membership of the PEC will carry significant organisational and legal responsibilities. There will therefore be a thorough induction programme for those elected, and ongoing training. Members will also have 'civil service' advice and support from the Chief Executive and his staff.

Next meetings of the PEC

Assuming the successful candidate is elected by the end of March at the latest, the next meetings of the PEC will be in London, commencing at $9.00 \mathrm{am}$, on Wednesday 19 March 2014 and Wednesday 14 May 2014.

\section{NEW NAME NOW OFFICIAL}

The British Dental Trade Association (BDTA) has now officially become the British Dental Industry Association (BDIA) (as of 1 January 2014), reflecting the increasing diversity of its membership and its ongoing commitment to actively driving quality standards throughout the industry.

BDIA Executive Director, Tony Reed, commented: 'The new name has driven a brand refresh upholding the Association's heritage and values. To communicate the change, the BDIA is launching an exciting new brand campaign promoting the diversity of its members and the benefits offered to the profession of choosing to do business with quality-conscious member companies'.
The BDIA

is the United

Kingdom's

largest

and most

authorita-

tive indus-

try body

represent-

ing manu-

facturers and suppliers of dental products, services and technologies. Over $20 \%$ of BDIA member companies are now involved in business, financial and publishing services.

The BDIA's strategy is focused on developing and delivering the services that will be of greatest business benefit to their changing membership. 